\title{
Estado nacional, petróleo e desenvolvimento: uma análise furtadiana
}

Silas Cardoso de Souza

\section{Resumo:}

O artigo visa a compreender o papel que o controle e a exploração do petróleo cumprem para os Estados nacionais, especialmente o brasileiro, situando-o na perspectiva do desafio furtadiano de superação do subdesenvolvimento, através da modificação das estruturas econômicas e sociais.

Palavras-chave: economia política - subdesenvolvimento - desenvolvimento petróleo - soberania econômica 
A discussão sobre forma de exploração das reservas de petróleo e gás natural voltou a figurar no centro da agenda política do país nos últimos anos com a descoberta de gigantescas jazidas deste hidrocarboneto na camada "pré-sal". Entretanto, o controle do petróleo perpassou todo o século XX como um elemento importante em guerras e disputas territoriais. O presente trabalho tenta contribuir para o debate sobre as relações entre desenvolvimento nacional e o gerenciamento estratégico desses recursos naturais, a partir de uma leitura estruturalista. Num primeiro momento, serão trazidos conceitos do pensamento de Gelso Furtado, importantes para compreender historicamente a formação de estruturas subdesenvolvidas como a brasileira. A partir desses conceitos, traçaremos um panorama da experiência desenvolvimentista nacional e da geopolítica do petróleo no século XX, de modo a entender o papel que esses recursos podem cumprir para a afirmação da soberania nacional e a superação do subdesenvolvimento.

\section{Estado nacional e desenvolvimento}

O projeto de desenvolvimento nacional inscrito na Constituição de I988 apoia-se em muitas das ideias do estruturalismo latino-americano, ${ }^{\mathrm{I}}$ escola de pensamento econômico que tem as suas raízes na CEPAL (Comissão Econômica para a América Latina e o Caribe). Mais do que influenciar a nossa Constituição, as ideias cepalinas fundamentaram os projetos de desenvolvimento de vários países da América Latina no século XX, inclusive no Brasil, a partir do segundo governo de Getúlio Vargas (BERCOVICI, 20IO).

A análise cepalina coloca o Estado como instrumento central para organizar e mobilizar forças políticas e sociais que permitam empreender um trabalho de reconstrução de certas estruturas próprias do subdesenvolvimento, através de uma visão sistêmica do desenvolvimento desigual do capitalismo (FURTADO, 2009a).

O Estado foi um elemento presente em todos os casos de "sucesso" de políticas de desenvolvimento no século XX, através da orientação estratégica para a formação e expansão de um "poder nacional". Neste século, o capitalismo apresentou uma tendência de crescente polarização e divergência entre

I Para uma discussão sobre o projeto de desenvolvimento nacional da Constituição de I988, ver BERCOVICI, 2005; e GRAU, 2007. 
as taxas de crescimento da economia e da renda per capita dos diferentes países, conforme a sua inserção na ordem econômica internacional e na divisão internacional do trabalho. Essa tendência só conseguiu ser revertida por meio da ação de Estados capazes de definir e sustentar projetos estratégicos a longo prazo (FIORI. In: FIORI; MEDEIROS, 200I).

Mesmo com a globalização econômica e a ideia de enfraquecimento das soberanias nacionais, ainda hoje o Estado constitui locus importante na disputa política para a concretização da superação do subdesenvolvimento. Nas palavras de Alessandro Octaviani:

Se o Estado-nação é pressuposto e consequência lógica da acumulação, é também um espaço a ser disputado pelas classes subalternas, e o Brasil seria um país onde esse exercício ainda pode ser viável (LUÍS, 2008, p. 36).

\section{I.I. Desenvolvimento e subdesenvolvimento}

O pensamento estruturalista vai enxergar a ciência econômica através de um duplo enfoque: o abstrato e o histórico (FURTADO, 2009a). O enfoque histórico ganha especial relevância no estudo da Teoria do Desenvolvimento, que, apesar de se valer de modelos econômicos, deve apresentar formulações específicas relativas a determinados processos históricos. Daí a rejeição de Celso Furtado à Teoria do Desenvolvimento concebida pelo mainstream econômico, que valoriza um enfoque abstrato de modelos em detrimento da dimensão histórica (FURTADO, 2009a).

Ao analisar o processo de desenvolvimento econômico europeu, Celso Furtado (2009a) identifica uma série de elementos históricos que o peculiariza. Esses elementos vão desde a chegada do comércio bizantino até o fenômeno histórico único da Revolução Industrial. A formação desse núcleo industrial na Europa do século XVIII provoca uma ruptura na economia mundial e condiciona o processo de desenvolvimento ao redor do globo a três grandes linhas. ${ }^{2}$

2 Toda a análise do desenvolvimento europeu, bem como das estruturas dele resultantes e sua completa caracterização encontram-se em FURTADO, 2009a, p. I6o. 
A primeira linha, dentro da própria Europa, constitui-se com a desorganização da economia feudal e com a incorporação dos fatores produtivos liberados num nível mais alto de produtividade. A segunda linha de desenvolvimento ocorre além das fronteiras europeias, em terras desocupadas e com características semelhantes às da Europa, onde vão prevalecer "colônias" com condições econômicas excepcionais. Em razão disso, a população desses espaços alcança um elevado nível de vida, semelhante ao dos países europeus.

Já a terceira linha de expansão da economia europeia desenvolve-se em direção a regiões já ocupadas por sistemas econômicos pré-capitalistas de diversas naturezas. Essa linha tem como resultante a criação do que Furtado chama de estruturas híbridas, com uma parte da economia comportando-se como um sistema capitalista e outra se mantendo dentro da estrutura preexistente. É justamente esse tipo de economia, resultante da penetração de empresas capitalistas em estruturas arcaicas, que constitui o problema do subdesenvolvimento contemporâneo.

Nas estruturas subdesenvolvidas, o fator externo é determinante como dinamizador da economia, e, ao contrário do que acontece nas estruturas desenvolvidas, a ação desse elemento é multiplicada internamente. ${ }^{3}$ No processo de industrialização dado no interior dessas economias ocorre uma falta de correspondência entre a tecnologia absorvida e a disponibilidade de fatores de produção. Esse arranjo permite, segundo Furtado (2009a), o desenvolvimento de um desequilíbrio estrutural da economia, na qual o emprego dos recursos disponíveis não é capaz de absorver toda a força de trabalho no nível de produtividade correspondente ao núcleo dinâmico do sistema. As estruturas subdesenvolvidas são híbridas, com grande heterogeneidade tecnológica entre os seus diferentes setores.

Outro conceito fundamental para o pensamento cepalino é o de sistema centro-periferia. A relação é estabelecida entre as estruturas desenvolvidas (centro) e as subdesenvolvidas (periferia), e está intimamente ligada à divisão internacional do trabalho, na qual algumas economias especializam-se na exportação de produtos primários, enquanto outras, com maior domínio do progresso tecnológico, colocam-se à frente no processo de industrialização, produzindo e exportando produtos industrializados de maior valor agregado. Os países fornecedores de produtos primários ligam-se ao centro do sistema através das suas exportações, constituindo uma vasta e heterogênea periferia.

3 Celso Furtado fala em um coeficiente de importação, que multiplica os impactos nos países subdesenvolvidos das mudanças cambiais nos países do centro do sistema econômico (FURTADO, 20ogb). 
Neste sistema, os ciclos econômicos das relações internacionais têm origem nos países industrializados e se propagam na esfera internacional. Os países agroexportadores, apesar de apresentarem um comportamento passivo, sentem de forma mais acentuada as flutuações nos níveis de atividade econômica (FURTADO, I992). Há uma tendência ao desenvolvimento polarizado entre estas duas partes do sistema, com as oportunidades de crescimento acelerado e de mudanças significativas no status quo se distribuindo de forma desigual entre os diferentes países e regiões (MEDEIROS. In: FIORI; MEDEIRO, 200I).

Essa dualidade centro-periferia sofre importante influência do ritmo e da forma de propagação do progresso técnico. Essa propagação pode se dar através da elaboração de processos produtivos mais eficazes ou pelo desenho de novos produtos que vão dar a face exterior da civilização industrial (FURTADO, 2009a).

Como fruto de um desequilíbrio na assimilação de novas tecnologias, as estruturas subdesenvolvidas têm maior facilidade de absorver as inovações que dizem respeito ao estilo de vida e aos padrões de consumo. Essa facilidade tem como contrapartida o atraso na absorção de técnicas produtivas mais eficazes. Já nas estruturas desenvolvidas, existe um paralelismo entre a absorção de tecnologia nesses dois setores. Os aumentos de produtividade e a assimilação do progresso técnico, dessa maneira, não conduzem à homogeneização social.

Pelo contrário, são inoculados padrões de comportamento e difundidos valores que têm pretensão universal, mas que nas economias subdesenvolvidas estão adstritos apenas a um setor da população, dada a heterogeneidade da estrutura econômica. A este processo, no qual a assimilação do progresso técnico ocorre quase que exclusivamente no plano do estilo de vida, com poucas transformações no sistema produtivo, Celso Furtado vai dar o nome de modernização. Via de regra, segundo o autor, a modernização agrava a concentração de renda, pois somente o setor afetado pelo aumento de produtividade vai desfrutar dos seus benefícios.

Exceção se dá quando há ação efetiva do Estado, no sentido da redistribuição da riqueza. Furtado aponta como exemplo os Emirados Petroleiros, com a ressalva de que, por ser o petróleo um recurso escasso e não renovável, as futuras gerações desses países encontrarão problemas na manutenção do seu nível de vida. Esse exemplo é particularmente importante para a discussão do presente trabalho, dado que é um dos desafios impostos ao Brasil, principalmente a partir das descobertas de petróleo na camada pré-sal. 


\section{I.II. Superação do subdesenvolvimento}

O período da Guerra Fria, durante a segunda metade do século XX, criou um cenário no qual condições externas favoráveis tornaram possíveis processos de industrialização acelerada, liderados pelo Estado e baseados em estruturas nacionais. É o que se chama de desenvolvimento a convite, estratégia estadunidense de promover o desenvolvimento de determinados países em regiões estratégicas no conflito com a União Soviética (MEDEIROS; SERRANO. In: FIORI, I999).

Dentre os convidados estavam a Alemanha, onde os Estados Unidos vão apoiar uma reconstrução da economia no período pós-guerra, e o Japão, que tem as dívidas de guerra perdoadas e sua indústria automobilística impulsionada. Coreia do Sul e Taiwan seguem o caminho japonês nos anos I96o, penetrando no mercado estadunidense. E, finalmente, a China, que vai, a partir dos anos I970, contar com uma abertura unilateral nas relações comerciais com os Estados Unidos, obtendo também apoio para a sua industrialização.

Ao analisar os processos de desenvolvimento dos países asiáticos, Furtado (I992) observa que o Estado chinês direcionou a acumulação de capital para o desenvolvimento das forças produtivas, dentro de um planejamento centralizado. Assim, cortou pela raiz o processo de modernização, satisfazendo as necessidades básicas da população, com um nível de renda per capita e um padrão de consumo comparativamente baixos, se contrastados com os do mundo desenvolvido. Já no caso sul-coreano e taiwanês, há uma primeira fase de preocupação social, com a promoção da reforma agrária e de intenso investimento no setor humano, especialmente na educação, o que vai interromper o processo de modernização quando este ainda estava num nível epidérmico.

Em comum, essas experiências asiáticas mostram que são condições necessárias para a superação do subdesenvolvimento a homogeneização social e a criação de um sistema produtivo eficiente, dotado de autonomia tecnológica.

A América Latina, por sua vez, permaneceu longe das zonas de maior conflito da Guerra Fria, recebendo assim pouca ajuda externa (FIORI; SERRANO. In: FIORI, I999). O financiamento externo para países latino-americanos aumenta a partir da Aliança para o Progresso, mas mesmo assim foi muito dependente de empresas multinacionais americanas e europeias.

$\mathrm{Na}$ década de I990, Celso Furtado diagnostica que o processo de desenvolvimento de um sistema econômico nacional já não está no caminho natural da nação brasileira. Com isso, vai fazer um chamado às próximas gerações para a superação do subdesenvolvimento. Bercovici (2009) e Octaviani (2008), ao incorporarem as análises de Furtado aos debates do Direito Econômico, falam na emergência de um desafio furtadiano. 


\section{I.III. O subdesenvolvimento brasileiro}

Para entender o que esses autores conceituam como o desafio furtadiano é necessário analisar a constituição do Brasil como território e Estado-nação, bem como o seu processo de industrialização dentro da competição interestatal dos países centrais e da expansão colonial europeia.

José Luís Fiori (I999) mostra que, na entrada do século XX, após o período liberal, de hegemonia inglesa, a periferia era atingida periodicamente por crises cambiais graves e baixas taxas de crescimento, sem capacidade de dinamização e integração social. Esse foi o caso da maioria dos países da América Latina, inclusive do Brasil. ${ }^{4}$ Até I930, o Brasil esteve completamente submetido ao sistema monetário e financeiro da Inglaterra, e espelhava as suas instituições no modelo político estadunidense. Já no período posterior, de transição da hegemonia inglesa para a estadunidense, o país começa a construção de uma economia nacional, mesmo que através de uma postura defensiva, em face das consequências da crise de I929 (FURTADO, 2009b; e FIORI. In: FIORI; MEDEIROS, 2OOI).

Celso Furtado (2009b) observa que o Brasil, durante a primeira metade do século XX, é marcado pela progressiva emergência de uma economia cujo centro dinâmico é o mercado interno. Verifica que, neste período, há uma redução substancial da importância relativa da procura externa como fator determinante do nível da renda. Esta seria a segunda etapa de um processo de desenvolvimento de uma região de escassa população e abundantes recursos naturais, caracterizada por uma intensa assimilação tecnológica, com mudanças substantivas na estrutura da economia.

O Brasil foi laboratório de uma estratégia associada e dependente de desenvolvimento, envolvendo o setor público, o capital privado nacional e internacional (EVANS, I982). O "desenvolvimentismo" aglutinou o apoio de quase todos os segmentos da classe dominante brasileira, e durante esse período o país manteve altas taxas de crescimento, com extensão da presença do Estado, de forma produtiva ou regulatória, aos mais importantes campos da atividade econômica. A criação da Petrobras (I953) é um dos símbolos do período.

O país passa por um forte processo de industrialização por substituição de importações (TAVARES, I972); entretanto, não houve a constituição de uma forte

4 Exceção eram os dominions ingleses, por terem uma política monetária administrada indiretamente pela Inglaterra, o que protegia os investimentos europeus. Esses países chegaram à entrada do século XX com renda per capita dentre as sociedades mais ricas do mundo. 
burguesia industrial, fato que Gilberto Bercovici (2010) apresenta como causa de manutenção da deterioração dos termos de troca. Furtado (2009a) e Medeiros (200I) apontam que a industrialização se fez ao custo da concentração de renda, com a constituição de uma economia de baixos níveis salariais na maior parte das atividades produtivas e forte endividamento estatal.

A partir do choque dos juros estadunidenses (I979) e da moratória mexicana (I982), a América Latina se vê privada de fontes externas de financiamento. O processo de crise econômica internacional, associada à crise política nacional do período final do regime militar, contribui para a ruptura do padrão de financiamento do Estado brasileiro (AFFONSO, I990), com o Estado assumindo as dívidas privadas. Essa ruptura vai levar ao que se chama de "crise fiscal", por sua vez agravada pela adoção posterior de políticas econômicas ortodoxas, que acabam por limitar as possibilidades de investimento público, inviabilizando políticas de desenvolvimento nas últimas décadas do século XX.

Fiori (200I) observa que os três governos que se seguiram ao período da ditadura militar (Sarney, Collor e Fernando Henrique Cardoso), principalmente o de FHG, levam à frente um projeto de transnacionalização da economia brasileira, legitimada pelo discurso neoliberal da falência do Estado, identificado com as ideias de ineficiência, burocracia, desperdício de recursos, morosidade e corrupção. ${ }^{5}$

Em paralelo às políticas recessivas de corte de investimentos, gastos sociais, aumento dos juros e redução do nível de emprego, houve, durante a década de I990, um intenso processo de desestatização. A venda de empresas estatais como Vale do Rio Doce e Companhia Siderúrgica Nacional e a abertura da economia para os atores privados em setores como a telefonia, mediante financiamento do BNDES, são marcas desse movimento. O setor de petróleo, como veremos à frente, foi atingido por esse processo de abertura, operado através da relativização do monopólio. Entretanto, a presença da Petrobras fez com que o Estado permanecesse com um importante instrumento de atuação no setor.

A desestatização leva a uma transferência dos centros decisórios, diminuindo o potencial do Estado de planejar e executar um projeto de desenvolvimento para o país, e submetendo setores estratégicos à lógica das empresas multinacionais, distantes do interesse público e do controle democrático sobre os setores estratégicos.

5 Para uma exposição sintética dessas ideias, ver BARROSO, 2006. 
O enfraquecimento do Estado brasileiro implica também numa redução dos espaços para as disputas políticas em torno da condução da economia. Pois é justamente a existência do Estado nacional, segundo Furtado (I992), que introduz a dimensão política nos cálculos econômicos. E é a prevalência dos critérios políticos sobre a lógica econômica que pode direcionar a ação dos agentes públicos e privados na busca da superação do subdesenvolvimento e do bem-estar coletivo.

\section{Geopolítica do petróleo}

No final do século XIX, o querosene, derivado do petróleo, começa a substituir o óleo de baleia como fonte de iluminação ao redor do mundo. Entretanto, o fator que primeiro define a importância do petróleo enquanto recurso estratégico no século XX é o militar, e não o econômico. A partir da Primeira Guerra Mundial, os derivados do petróleo são percebidos como o meio mais eficiente para mover as forças armadas. Depois da Segunda Guerra, com a difusão do American way of life e do uso de carros, aviões, navios e trens, a economia vai de uma vez por todas se "petrolizar", com esse combustível despontando enquanto principal fonte energética (TORRES FILHO, 2005).

Dados de 2010 mostram que o petróleo e o gás são responsáveis por $54,3 \%$ da oferta mundial de energia. Números que impressionam, mas que são ainda menores que os 62,I\% que estas fontes representavam em 1973 (BARROS et al., 20IO). Dentre os fatores que explicam esta queda está a volatilidade de preços, derivada das mudanças no cenário geopolítico nas últimas décadas do século XX. Essa volatilidade liga-se à intensa disputa pelo controle deste recurso estratégico entre Estados produtores, as grandes companhias petroleiras e a potência global dominante, os Estados Unidos.

Autores estudados (TORRES FILHO, 2005; BARROS et al., 20IO; FERREIRA, 2005) convergem na periodização em três fases do mercado mundial de petróleo a partir da Segunda Guerra Mundial.

A primeira fase, que vai de I 945 a I973, coincide com a "época de ouro" de crescimento da economia mundial capitalista. O mercado de petróleo é caracterizado por um forte crescimento da demanda (cerca de $7 \%$ ao ano). Apesar desse aumento na procura, os preços do hidrocarboneto mantêm-se estáveis com tendência à queda, dado que a produção de petróleo cresce ainda mais rapidamente, principalmente nos países de terceiro mundo.

A estabilidade do mercado sustenta-se em dois arranjos institucionais (BARROS et al., 20IO): (i) acordos firmados entre as grandes empresas pro- 
dutoras estabelecendo as regras para operação conjunta no Oriente Médio; e (ii) os contratos de concessão firmados entre essas empresas e os países da região, que garantiam a partilha de resultados, destinando $50 \%$ a cada parte, empresas e governos. A segurança desse duplo arranjo garantiu-se pelo condomínio econômico-militar anglo-americano formado no Oriente Médio.

$\mathrm{O}$ quadro de estabilidade começa a se modificar, entretanto, com a volta da União Soviética ao mercado, no final da década de I960, com a insatisfação de empresas petroleiras excluídas dos acordos com os países produtores e, principalmente, com a criação da OPEP (Organização dos Países Produtores de Petróleo) em I960. Ocorre, assim, aumento abrupto da oferta, e, com a entrada da União Soviética no mercado e a utilização da capacidade ociosa dos Estados Unidos e do Oriente Médio, opera-se uma queda de preço seguida de reação dos países exportadores.

A partir dos anos 1970 , os países membros da OPEP implementam medidas efetivas no sentido de aumentar o seu controle sobre o mercado de petróleo. Através de uma política denominada "participação direta", esses países, baseados no princípio da soberania nacional sobre os recursos naturais, ${ }^{6}$ vão construir companhias nacionais de petróleo e adquirir os direitos sobre as reservas outrora concedidas às petroleiras.

Dessa forma, o mercado mundial de petróleo do pós-guerra entra numa segunda fase, marcada pela drástica redução do controle das multinacionais sobre as reservas, crescente intervenção estatal, flutuação dos preços e restrita capacidade ociosa (TORRES FILHO, 2005). O marco inicial dessa fase é o primeiro choque do petróleo, em I973, com a eclosão de nova guerra árabe- israelense, a Guerra de Outubro, num momento em que a capacidade ociosa era de apenas I\% da demanda mundial por petróleo.

A mudança de estratégia da Arábia Saudita em I985, com a fixação de um determinado volume de produção independente do preço de mercado, e o contrachoque do petróleo em I986 (com o barril chegando a US\$ II,50) vão

6 A soberania dos Estados nacionais sobre os recursos naturais foi reconhecida pela ONU, a partir de um processo de disputa que colocava de um lado os países subdesenvolvidos, detentores desses recursos, e do outro os Estados Unidos e as empresas multinacionais, que manifestaram forte oposição a este reconhecimento. A Resolução da ONU no 656, de I962, foi a primeira a afirmar a defesa do princípio da soberania e o direito dos países de dispor livremente das suas riquezas naturais para fins de desenvolvimento econômico. Em I962, essa mesma organização aprovaria a Resolução no I.803, que garantia o direito à nacionalização como forma dos países recuperarem os seus recursos naturais, fundados no exercício do seu poder soberano. 
dar início à terceira fase na ordenação dos mercados, baseada em preços flexíveis. A Arábia Saudita, dona dos menores custos de produção em todo o mundo, torna-se o principal player desse período.

A terceira fase é marcada por uma onda liberalizante, também no setor de petróleo. Boa parte das estatais ao redor do mundo são privatizadas, e os mercados são progressivamente liberalizados. Como palavras-chave desse momento teremos a produtividade e a eficiência. A carência de recursos financeiros e os altos riscos envolvidos na exploração do petróleo vão levar governos a recorrerem à iniciativa privada.

\section{II.I. Panorama brasileiro}

Como vimos anteriormente, no período que sucede a Primeira Guerra Mundial, o petróleo converte-se em um problema econômico e, principalmente, militar. Nesse período, a economia brasileira passa por mudanças estruturais, com o eixo dinâmico se deslocando para a indústria, pressionando assim a demanda por bens energéticos. A política brasileira para o petróleo, nesse contexto, visa a atender ao binômio segurança-desenvolvimento (BARROS et al., 20IO). Vai haver ainda, a partir dos anos I930, uma orientação de caráter nacionalista, com o fim de proteger a economia nacional das oscilações internacionais, que influencia nas disputas sobre o controle das jazidas minerais e especialmente do petróleo.

É nesse sentido que é promulgado o Código de Minas (Decreto $24.642 / 34$ ), que separa a propriedade do subsolo da propriedade do solo, nacionalizando-a. Em I938, através do Decreto-Lei 395, Getúlio Vargas declara o abastecimento de petróleo como de utilidade pública nacional, nacionalizando a indústria de refino e criando o Conselho Nacional de Petróleo. Em seguida edita o Decreto-Lei 3.236/4I, para declarar que todas as jazidas de petróleo e gás pertencem, em caráter imprescritível, à União.

Em torno do Centro de Estudos em Defesa do Petróleo e da Economia Nacional organiza-se um forte movimento nacionalista, que lança a histórica campanha "O petróleo é nosso", defendendo o monopólio estatal sobre a indústria. O argumento desses nacionalistas (BARROS et al., 20IO) era que apenas uma empresa estatal, verticalmente integrada, poderia aumentar consideravelmente a produção nacional de petróleo, ainda incipiente à época. Somente este ente estaria disposto a distribuir riscos e custos de modo a balancear os segmentos upstream (exploração e produção) e downstream (refino, transporte, distribuição e comercialização). 
Mais que isso, havia uma forte orientação desenvolvimentista, preocupada com a inserção brasileira no comércio internacional e com a capacidade de decisão do Estado brasileiro. Não à toa, Gelso Furtado utiliza o "Caso do petróleo" como exemplo de um processo de diferenciação nacional no quadro da economia mundial (FURTADO, I992).

No início de seu segundo governo, Getúlio Vargas elabora uma política nacional de petróleo, cuja principal medida seria a criação de uma empresa estatal. A proposta de criação da Petrobras foi enviada em I95I para o Congresso Nacional, através de uma mensagem ao Congresso que nitidamente incorporava conceitos que seriam posteriormente desenvolvidos pela escola econômica estruturalista, como a deterioração dos termos de troca, a internalização dos centros de decisão e a integração da politica do petróleo ao processo de industrialização do país (BERCOVICI, 20IO).

Em I953, o Congresso Nacional aprova a Lei 2.004, que cria a Petrobras e declara o monopólio da União sobre a pesquisa, lavra, refino e transporte de petróleo, gás e seus derivados. O objetivo declarado da estatal, sociedade de economia mista, era o de garantir a autossuficiência nacional (BARROS et al., 20IO). Na presidência de João Goulart (I96I-I964), o monopólio estatal estendeu-se às exportações e importações de petróleo e derivados. A concentração de todas essas atividades em uma mesma empresa aumentava o poder de negociação da Petrobras, e permitia a implementação de uma política industrial unificada no setor de transportes, incorporando centros de decisão ao Estado e integrando a política para o petróleo com o planejamento estatal.

Com a reforma administrativa implementada pelo regime militar ( $\mathrm{De}-$ creto-Lei 200/I967), a Petrobras ganha ainda maior autonomia e concentra as suas atividades no segmento downstream (refino e distribuição), reforçando seus setores mais rentáveis, mas estagnando a produção de petróleo no país (BARROS et al., 20IO). A mudança de eixo causada por essa reforma faz com que as estatais, dentre elas a Petrobras, passem a atuar não como instrumentos de política econômica do governo, mas como atores de mercado (BERGOVICI, 20IO). Com isso, a estratégia que antes priorizava a exploração e produção de petróleo, reorienta-se no sentido de diversificação dos investimentos. Nota-se, aqui, um recuo da dimensão política dos cálculos econômicos. Trata-se, exatamente, da racionalidade apontada por Celso Furtado como condição para a superação do subdesenvolvimento (ver item I.3). Entretanto, a reorientação dos investimentos, associada ao planejamento estatal presente no II PND, trouxe como consequência positiva o surgimento de uma forte indústria petroquímica no país (BERCOVICI, 20IO). 
Com as restrições impostas para os financiamentos do BNDE durante o regime militar, as estatais são estimuladas a se endividarem no exterior (AFFONSO, I990; BERCOVICI, 20IO). Com o choque dos juros nos anos I970, elas são utilizadas para a estabilização macroeconômica do país. Esse fator, somado aos dois choques do petróleo (I973 e I979), faz com que a Petrobras passe por um momento difícil e sofra pressões desestatizantes nas décadas posteriores (BARROS et al., 20IO). Em I975, Geisel e o Conselho Nacional do Petróleo dão um passo nesse sentido ao abrirem a possibilidade de outorga a empresas privadas dos riscos das operações de exploração do petróleo. Através destes "contratos de risco" as empresas obtinham a concessão para a exploração, mas não para a produção da reserva.

O monopólio estatal, que havia sido elevado a nível constitucional em I967, é mantido sob a Constituição de I988. Entretanto, Fernando Collor de Mello, primeiro presidente eleito sob a nova Carta, inclui as subsidiárias da Petrobras no PND (Programa Nacional de Desestatização). O governo posterior, de Fernando Henrique Cardoso, implementa mudanças ainda mais profundas no sentido da abertura e liberalização do mercado de exploração e produção de petróleo. Essas mudanças são operadas a partir da Emenda Constitucional $\mathrm{n}^{\circ}$ 09/95, que abre a possibilidade de contratação, por parte da União, de empresas públicas ou privadas para a exploração e produção de petróleo, relativizando, assim, o monopólio estatal nestes setores.

A Lei 9.478/97, por sua vez, institui o marco regulatório dentro do qual essas atividades serão realizadas. É criada a Agência Nacional do Petróleo (ANP), que organiza as licitações através das quais as empresas concorrem pelos blocos disponíveis. Essa autarquia, estruturada dentro de um modelo institucional que lhe confere maior autonomia, ${ }^{7}$ celebra contratos de concessão em nome da União e tem a competência de fiscalizá-los e aplicar penalidades. As concessionárias assumem o risco da exploração e, em caso de sucesso, apropriam-se do produto da lavra, pagando participações governamentais à União, além de um bônus de assinatura, previsto no processo licitatório.

As mudanças instituídas na década de I990 transformam o perfil da atuação estatal no setor, que passa de agente econômico a agente fiscalizador e regulador. A participação governamental na formulação da política para a indústria petrolífera continua presente com a criação do CNPE (Conselho

7 Para uma descrição sobre a autonomia e o âmbito de atuação das agências reguladoras ver ARDENGHY, 2005; e MENEZELLO, 2000. 
Nacional de Política Energética). Todavia, a relativa independência da agência reguladora, a forma de execução dos contratos e a perda da titularidade sobre o óleo bruto diminuem a possibilidade de planejamento e controle sobre o ritmo da produção e exportação. Observa-se, assim, uma retirada relativa do âmbito estatal dos centros de decisão, assim como uma tendência à sua internacionalização, uma vez que, à exceção da Petrobras, são multinacionais as principais empresas que operam no setor.

Com a descoberta das reservas da camada pré-sal, em 2007, voltou à tona o debate sobre a forma de exploração dos recursos petrolíferos. O gigantismo das reservas reposicionou o Brasil no cenário internacional do petróleo, elevando o país à condição de detentor de uma das dez maiores reservas do mundo, atrás somente de Rússia, Venezuela e de parte dos países do Oriente Médio (BARROS et al., 20IO, p. 467). Esse novo cenário, associado ao baixo risco exploratório e a uma mudança de orientação política a partir dos governos de Luiz Inácio Lula da Silva (2003-20IO), leva a uma nova alteração do marco regulatório, abrindo novas perspectivas para a forma de apropriação e utilização dos recursos petrolíferos.

Foi instituído, com a Lei I2.35I/IO, o sistema de partilha de produção para as áreas do pré-sal. Os contratos de partilha mantêm a participação da iniciativa privada através da licitação de blocos petrolíferos, mas garantem a propriedade estatal sobre os hidrocarbonetos antes de sua comercialização, distribuindo os riscos e a captura da renda proporcionalmente entre Estado e concessionário, de acordo com os seus respectivos aportes de capital. A Petrobras é participante obrigatória de todos os consórcios formados para a exploração e produção das áreas, podendo também ser contratada diretamente, sem licitação. A mesma lei autorizou a criação do Fundo Social, dando a este instrumento a finalidade de constituir uma fonte de recursos para a utilização da renda petrolífera para o desenvolvimento social e regional, a partir do apoio a projetos de desenvolvimento e de combate à pobreza.

É comum, em países ricos em recursos naturais, a criação dos fundos soberanos de riqueza (sovereign wealth funds), que nada mais são que fundos de investimento dos Estados que têm pouca necessidade de liquidez imediata e grande quantidade de reservas cambiais. Nos últimos anos, com o boom nos preços das commodities e os déficits estadunidenses, esses fundos ganharam grande importância no cenário internacional (SIAS, 2008, p. 93-I27). Gilberto Bercovici (20IO, p. 346) aponta que a criação de fundos de investimento é o método mais prático de transformar um recurso natural não renovável, como o petróleo, em recurso renovável. Essa transformação se dá através do investimento das rendas obtidas na extração mineral ou petrolífera, 
de modo a aumentar a capacidade produtiva de futuras gerações, perenizando, assim, os frutos dos recursos finitos.

Os recursos do Fundo Social poderão ser aplicados em educação, cultura, esporte, saúde pública, ciência e tecnologia e meio ambiente, conforme disposto nos incisos do artigo 47 da referida Lei. O percentual dos recursos a ser destinado a cada uma das áreas não está disposto em lei, ficando em aberto, portanto, a discussão sobre as prioridades efetivas do Estado.

Verifica-se, com o regime de partilha, um movimento em sentido contrário ao da década de I990, no que diz respeito à atuação estatal na cadeia petrolífera. Há um reforço dos centros decisórios no Estado nacional e aumento da apropriação estatal do excedente gerado pela atividade.

A concentração dos centros decisórios no Estado implica num maior controle sobre a cadeia produtiva e do ritmo de exploração do petróleo. Existem diversas nuances ao longo dessa cadeia que abrem a possibilidade da implementação de uma política industrial e tecnológica voltada às reais necessidades da nação para a superação da condição de subdesenvolvimento. Exemplo é a política de priorizar o conteúdo local nas compras da Petrobras, que fez triplicar para $55 \%$ o conteúdo nacional dos equipamentos de exploração e produção da empresa (Folha de S.Paulo, 20I2). O controle do ritmo de exploração, por sua vez, submete a atividade petrolífera ao planejamento de médio e longo prazos. Com isso é aberta a possibilidade de avaliar estrategicamente se é melhor, em determinada conjuntura, a exploração rápida ou a manutenção das jazidas enquanto lastro econômico para o país.

\section{Considerações finais}

O debate sobre o controle estatal do petróleo diz respeito principalmente à soberania econômica de um país e à internalização dos centros de decisão, e não só a questões de eficiência e produtividade, conceitos próprios das análises mercadológicas. Excluir os referidos elementos é concentrar a leitura numa chave de análise economicista, desconsiderando as necessidades de uma economia subdesenvolvida como a do Brasil, que tem tarefas constitucionais a cumprir para com a sua população, como a erradicação da miséria, a diminuição das desigualdades regionais e a garantia de direitos básicos como educação, saúde e moradia.

O gerenciamento da exploração e produção de petróleo envolve questões estratégicas que dizem respeito ao desenvolvimento do país e à sua inserção no cenário internacional, e por isso deve estar sob o comando do Estado. Dentre essas questões está o controle do volume de exportação, que entra em 
conflito com os interesses do mercado internacional, que pressiona do lado da demanda. Outro problema é a forma de inserção nas cadeias produtivas, através da qual se pode fazer política industrial com a geração de competências tecnológicas próprias através da produção de conteúdo local (BARROS et al., 2010).

O arcabouço teórico estruturalista, bem como a análise dos panoramas mundial e brasileiro da política de petróleo no século XX, demonstram que os recursos naturais, especialmente o petróleo, são importantes como objeto da economia política. O estudo de teóricos e a análise da geopolítica desse hidrocarboneto dão conta de sua decisiva interferência nas relações sociais e econômicas de uma sociedade (BERCOVICI, 20IO), conduzindo numa direção ou noutra no processo de rompimento com a condição de subdesenvolvimento.

O desafio furtadiano está em compreender a formação desse cenário descrito e, a partir disso, buscar soluções para a superação do subdesenvolvimento. No caso brasileiro, o controle estatal sobre a indústria do petróleo esteve intimamente ligado ao processo de industrialização pelo qual o país passou no século passado. Nos dias de hoje, relaciona-se com a possibilidade de superação de entraves tecnológicos, geração de dinamismo econômico e com a distribuição do excedente advindo da exploração.

\section{Referências bibliográficas}

AFFONSO, Rui de Britto Álvares. A ruptura do padrão de financiamento do setor público e a crise do planejamento no Brasil dos anos 80. Planejamento e Políticas Públicas, Brasília, IPEA, n. 4, dez. I990.

ARDENGHY, Roberto Furian. As agências reguladoras e o princípio da legalidade: o caso da Agência Nacional do Petróleo. In: PIRES, Paulo Valois (Org.). Temas de direito do petróleo e do gás natural II. Rio de Janeiro: Lumen Juris, 2005 .

BARROS, Pedro Silva; SCHUTTE, Giorgio Romano; PINTO, Luiz Fernando Sanná; FUSER, Igor; REIS, Solange. Além da autossuficiência: o Brasil como protagonista do setor energético. In: ACIOLY, Luciana; CINTRA, Marcos Antonio Macedo (Org.). Inserção internacional brasileira soberana. Brasília: IPEA, 2OIO, v. I.

BARROSO, Luís Roberto. Modalidades de intervenção do Estado na ordem econômica. Regime jurídico das sociedades de economia mista. Inocorrência de abuso de poder econômico. In: Temas de direito constitucional. 2. ed. Rio de Janeiro: Renovar, 2006, tomo I. 
BERCOVICI, Gilberto. Constituição econômica e desenvolvimento: uma leitura a partir da Constituição de I988. São Paulo: Malheiros Editores, 2005.

. O ainda indispensável direito econômico. In: BENEVIDES, Maria Victoria de Mesquita; BERCOVICI, Gilberto; MELO, Glaudineu de (Org.). Direitos humanos, democracia e república: homenagem a Fábio Konder Comparato. São Paulo: Quartier Latin, 2009.

. Petróleo, recursos minerais e apropriação do excedente. São Paulo: USP, 20IO. Tese de titularidade apresentada à Faculdade de Direito da Universidade de São Paulo, São Paulo, 2010.

GLÈVE, Clèmerson Merlin; MARTINS, Alessandra Ferreira. Princípios constitucionais da atividade econômica petrolífera e Lei 9.478 de I997. A\&G-Revista de Direito Administrativo e Constitucional, Belo Horizonte, Fórum, n. I8, p. 43-50, out./dez. 2004.

FERREIRA, Antônio Luís de Miranda. A desmonopolização do mercado. In: PIRES, Paulo Valois (Org.). Temas de direito do petróleo e do gás natural II. Rio de Janeiro: Lumen Juris, 2005.

EVANS, Peter. A tríplice aliança: as multinacionais, as estatais e o capital nacional no desenvolvimento dependente brasileiro. Rio de Janeiro: Zahar, I982.

FIORI, José Luís (Org.). Estados e moedas no desenvolvimento das nações. 2. ed. Petrópolis: Editora Vozes, I999.

; MEDEIROS, Carlos de Aguiar (Org.). Polarização mundial e crescimento. Petrópolis: Editora Vozes, 200I.

FOLHA DE S.PAULO. Conteúdo nacionalista. São Paulo, I2 jun. 20I2. Opinião, Editorial, p. 2.

FURTADO, Celso. Brasil: a construção interrompida. 2. ed. Rio de Janeiro: Paz e Terra, I992.

- Desenvolvimento e subdesenvolvimento. Rio de Janeiro: Contraponto/Centro Editorial Celso Furtado, 2009a.

. Formação econômica do Brasil [edição comemorativa 50 anos]. São Paulo: Companhia das Letras, 2009b.

GRAU, Eros Roberto. A ordem econômica na Constituição de 1988: interpretação e crítica. I2. ed. São Paulo: Malheiros Editores, 2007.

LUÍS, Alessandro S. Octaviani. Recursos genéticos e desenvolvimento: os desafios furtadiano e gramsciano [mimeo]. São Paulo: USP, 2008. Tese de doutoramento da Faculdade de Direito da Universidade de São Paulo, São Paulo, 2008.

MENEZELLO, Maria D’Assunção Costa. A regulação e o direito do petróleo: introdução ao direito do petróleo e gás. In: SUNDFELD, Carlos Ari (Org.). Direito administrativo econômico. São Paulo: Malheiros Editores, 2000. 
MORAES, Alexandre de. Regime jurídico da concessão para exploração de petróleo e gás natural. Revista de Direito Constitucional e Internacional, São Paulo, RT, n. 36, jul./set. 200I, p. I62-I76.

SIAS, Rodrigo. O Fundo Soberano Brasileiro e suas implicações para a política econômica. Revista do BNDES, Rio de Janeiro, v. I5, n. 30, dez. 2008, p. 93-I27.

TAVARES, Maria da Conceição. Da substituição de importações ao capitalismo financeiro. Rio de Janeiro: Zahar, I972.

TORRES FILHO, Ernani Teixeira. O papel do petróleo na geopolítica americana. In: FIORI, José Luís (Org.). O poder americano. 2. ed. Petrópolis: Editora Vozes, 2005.

Silas Cardoso de Souza - Mestrando em Direito Econômico pela Universidade de São Paulo.

silas_cs@hotmail.com 